\title{
Hard Tissue-Forming Ability and Ultra-Micro Structure of Newly Developed Sponges as Scaffolds Made with Sodium Alginate Gel and Chondroitin Sulfate
}

\author{
Ayano Miyamoto, Masataka Yoshikawa, Hiroshi Maeda \\ Department of Endodontics, Osaka Dental University, Osaka, Japan \\ Correspondence to: Ayano Miyamoto, miyamoto-a@cc.osaka-dent.ac.jp \\ Keywords: Sodium Alginate Sponge, Osteogenesis, Stem Cells, Chondroitin Sulfate, In Vivo, In Vitro \\ Received: October 15, $2018 \quad$ Accepted: November 11, $2018 \quad$ Published: November 14, 2018 \\ Copyright () 2018 by authors and Scientific Research Publishing Inc. \\ This work is licensed under the Creative Commons Attribution International License (CC BY 4.0). \\ http://creativecommons.org/licenses/by/4.0/ \\ (c) (i)
}

\section{ABSTRACT}

To regenerate teeth and bones, a scaffold is essential. Hydroxyapatite has been used in many studies, but scaffolds made of hydrogel or sponge are also effective. The hardness of hydroxyapatite is a disadvantageous property for shaping. A sponge is suitable as a scaffold because the shape of the scaffold can be matched to the defect. Sodium alginate (AL) has excellent biocompatibility and a sponge can be made from this gel by lyophilization. The purpose of this study was to promote hard tissue formation with a sponge made of AL gel or AL gel and chondroitin sulfate (Chs). Sponges were made from AL gel, which were then used as a scaffold to investigate their effectiveness for the formation of hard tissue or bone. Hard tissue formation in the pores of these AL sponges was estimated in vitro and in vivo. In the sponge made from $\mathrm{AL}$ gel, the concentration of $\mathrm{AL}$ and the addition of Chs affected bone formation. Concentration of AL would affect the shape and size of the pores. ALP activity in the sponges was also enhanced by Chs. The amount of osteocalcin (OC) produced in the sponge by rat bone marrow cells increased depending on the $\mathrm{AL}$ and Chs concentrations in the gel. The level of $\mathrm{OC}$ amount in the sponges made from AL gel containing Chs was notable in vivo. Bone formation in the sponge in vivo was affected by the addition of Chs in AL gel. The quantity of OC and the bone formation in AL sponges in subcutaneous tissue in vivo suggested that $\mathrm{AL}$ sponges can be useful as a scaffold.

\section{INTRODUCTION}

In dentistry, partial defective restoration of the hard tissue of the tooth, prosthesis for the loss of all or several teeth, and reconstruction of the resorption of alveolar bone due to a periapical lesion or periodontal disease are important treatments. Restoration of hard tissue defects by tissue engineering is desired in 
dentistry. Previous studies assessed the reconstruction of teeth [1, 2], and reconstruction of bone [3, 4] has been performed. Functional restoration has been performed for hard tissue defects of teeth using current dental treatments. However, reconstruction of teeth with physiological function is desired [5]. Regeneration of teeth including the periodontal ligament may give teeth physiological functionality [6]. Thus, regeneration of such teeth is the ideal result of tissue engineering treatment. On the other hand, the reconstruction of the resorption of alveolar bone due to disease is considered difficult. In the future, absorbed bones may be reconstructed easily using one of the processes of tissue engineering.

The structure of most tissues and organs is three-dimensional. The three-dimensional culture of appropriate cells or the use of a scaffold may enable their regeneration [7]. Application of a scaffold is considered to be particularly useful for the regeneration of teeth and bone. Proliferation and differentiation of stem cells for regeneration should be induced in the scaffold [8]. For the scaffold to be applied to the reconstruction of a tooth or bone defect, properties which allow for easy structural replication of the defect are desired. Therefore, scaffolds with superior molding capability are needed. A scaffold that can be shaped according to the defect during treatment is convenient, and a biodegradable sponge scaffold that is eventually replaced by surrounding tissue is more desirable.

Poly-L-lactic acid [9], polyvinyl alcohol [10] and sodium alginate (AL) [11,12] are reported as sponge scaffold materials. Several kinds of AL and its derivatives as hydrocolloids are used for food [13], medicines $[14,15]$ and biomaterials $[16,17]$. AL originates from a plant. AL is known to have excellent biocompatibility [18], and hard tissue formation using AL sponges was previously reported [19, 20]. AL has a strong affinity with water and is used as a thickening or gelling agent [21]. AL can also be used in oral sustained-release beads [22, 23] or a scaffold [24]. Based on these reports, the use of AL sponges as biomaterials may be feasible. Therefore, several types of sponges were prepared in this study, and their use as scaffolds for osteogenesis was evaluated in vitro and in vivo.

In this study, sponges were made from AL gel containing a chondroitin sulfate A sodium salt (Chs). Chs is a mucopolysaccharide existing as an intercellular substrate. Based on the results of hard tissue formation in the apical root canals of rat mandibular molars in the previous in vivo study, the chemical substrate was considered to be able to induce hard tissue [25]. It usually exists as a proteoglycan that is covalently linked to a core protein. As the proteoglycan called aggrecan, Chs mainly exists in the extracellular matrix of cartilage and in connective tissues such as skin. A small amount of Chs was added into the AL gel before making the sponges to promote adhesion of the stem cells to the AL sponge.

The promotion of hard tissue formation with a sponge made of AL gel or AL gel including Chs was the purpose of this study. Hard tissue formation in the pores of these AL sponges as the scaffold was estimated in vitro and in vivo.

\section{MATERIALS AND METHODS}

\subsection{Preparation of AL Gel}

The AL was dissolved at 4\% (1000 cps: Nacalai-Tesque: Kyoto, Japan), 8\% (500 cps: FUJIFILM Wako Pure Chemical Corp., Osaka, Japan) or 10\% (500 cps: FUJIFILM Wako Pure Chemical Corp.) (w/v) in ultra-purified water. The $4 \%, 8 \%$ and $10 \% \mathrm{AL}$ gels were autoclaved for sterilization at $121^{\circ} \mathrm{C}$ for 20 minutes. In $5 \mathrm{ml}$ of ultra-purified water, $10 \mathrm{~g}$ of Chs (M.W.:10,000 - 150,000 in an average, FUJIFILM FUJIFILM Wako Pure Chemical Corp.) was dissolved. The solution was sterilized by filtration (Millex-GS ${ }^{2} ; \phi 0.22$ $\mu \mathrm{m}$ : Merck \& Co. Inc., NJ, USA). The Chs solution was mixed with sterilized $10 \%$ AL gel at a final concentration of $1 \%$ or $10 \%$. In total, five types of gels were prepared. To prepare the $1 \%$ Chs containing $10 \% \mathrm{AL}$ gel, $0.5 \mathrm{ml}$ of Chs solution was added to $9.5 \mathrm{ml}$ of $10 \% \mathrm{AL}$ gel (1\%Chs-10\%AL gel), and to prepare the $10 \%$ AL gel containing $10 \%$ Chs (10\%Chs-10\%AL gel), $0.5 \mathrm{ml}$ of Chs solution was mixed with $9.5 \mathrm{ml}$ of $10 \% \mathrm{AL}$ gel.

\subsection{Preparation of AL Sponge Scaffolds and Microstructural Observation by SEM}

Each gel was poured into a ring made of stainless steel with a 6-mm inner diameter, 8 -mm outer 
diameter and height of $10 \mathrm{~mm}$. The gels in the ring were frozen at $-80^{\circ} \mathrm{C}$ for 6 hours. The frozen gels were taken out from the ring and immersed in a 1\% calcium chloride solution (w/v) for 6 hours for chemical cross-linking. They were frozen again and freeze-dried with a vacuum (Freeze Dryer DC800, Yamato Scientific Co. Ltd, Tokyo, Japan) for 12 hours. Through these processes, five types of AL sponges (4\%AL Sponge, $8 \%$ AL Sponge, 10\%AL Sponge, 1\%Chs-10\%AL Sponge and 10\%Chs-10\%AL Sponge) were made.

The ultra-micro structure of each sponge was observed with a scanning electron microscope (SEM: Field emission scanning electron microscope S4800, HITACHI; Hitachi High-Technologies Corporation, Tokyo, Japan).

\subsection{Experimental Animals}

This study was performed under the Guidelines for Animal Experimentation at Osaka Dental University. Regarding the use and care of the animals, the Animal Welfare Committee of Osaka Dental University approved the experimental procedures.

Male Fischer 344 rats were kept in standard rat cages with free access to dry pellets and water with unrestricted movement at all times during feeding. All surgical procedures were performed under general anesthesia by inhalation of isoflurane (Forane ${ }^{\circledR}$; Abbott Japan Co. Ltd., Tokyo, Japan). At the time of harvesting bone marrow cells from the rat femur or at completion of the experimental period for the subcutaneous implantation of scaffolds, the animals were euthanized by excessive inhalation of isoflurane.

\subsection{Rat Bone Marrow Cell Isolation and Preparation of the Cell Suspension}

Rat bone marrow cells (rBMCs) were obtained from the bone shafts of the femora of 6-week-old male Fischer 344 rats (Japan SLC, Inc., Shizuoka, Japan) after euthanasia by excessive inhalation of isoflurane. Both ends of the femur were cut off at the epiphysis, and bone marrow was flushed out with $10 \mathrm{ml}$ of minimum essential medium (D-MEM containing L-glutamine and phenol red: FUJIFILM Wako Pure Chemical Corp., Osaka, Japan) expelled from a syringe through a 21-gauge needle. The MEM used for the cell culture was supplemented with $15 \%$ fetal bovine serum (FBS; Biocera Inc., MO, USA) and antibiotics (100 units $/ \mathrm{ml}$ of penicillin, $100 \mu \mathrm{g} / \mathrm{ml}$ of streptomycin and $0.25 \mu \mathrm{g} / \mathrm{ml}$ of amphotericin B, Sigma-Aldrich Co., MO, USA). Primary culture of rBMCs was performed for 10 days in a cell culture flask (T-75; BD Biosciences, MA, USA) in an incubator at $5 \% \mathrm{CO}_{2}$ and $95 \%$ relative humidity at $37^{\circ} \mathrm{C}$. The medium was renewed 3 times during the culture period.

After primary culture, rBMCs in T-75 culture flasks were washed three times using phosphate-buffered solution without $\mathrm{Ca}^{2+}$ and $\mathrm{Mg}^{2+}$ (PBS (-); Thermo Fisher Scientific, Inc.). The cells were isolated from the bottom of the T-75 flasks with $2 \mathrm{ml}$ of trypsin-EDTA solution $(0.05 \mathrm{w} / \mathrm{v} \%$ Trypsin- 0.53 mmol/l EDTA-4Na solution with phenol red: FUJIFILM Wako Pure Chemical Corp.) and incubation for 3 hours at $37^{\circ} \mathrm{C}$. The cells attached to the bottom were dispersed in MEM by shaking the T-75 flask. To stop the effects of trypsin, $8 \mathrm{ml}$ of MEM containing FBS was poured into the flask. The cells were transferred to a centrifuge tube and washed three times by centrifugation at $120 \times \mathrm{g}$ using $20 \mathrm{ml}$ of PBS (-). Then, for the preparation of the rBMC suspension, rBMCs were re-suspended in MEM containing 15\% FBS at a density of $1 \times 10^{6}$ cells $/ \mathrm{ml}$.

\subsection{In Vitro Hard Tissue Formation by rBMCs in the AL Sponge Scaffolds}

\subsubsection{Seeding of rBMCs in the Scaffolds for Subculture}

rBMCs at $2 \times 10^{5}$ cells were seeded in each AL sponge $(n=6)$ by soaking with $200 \mu$ of the prepared rBMC suspension. The sponges were kept in an incubator for 1 hour to ensure attachment of the cells to the pore walls of the sponge. Then, the sponges containing rBMCs were immersed in $1.5 \mathrm{ml}$ of MEM in a 24 -well micro-plate for 3 weeks. The medium was renewed 3 times a week. At the time of exchange of culture medium, $1 \mathrm{mmol} \beta$-glycerophosphate, $82 \mu \mathrm{g}$ of ascorbic acid and $10 \mathrm{nmol}$ dexamethasone in $10-\mu \mathrm{l}$ aliquots were added to $1 \mathrm{ml}$ of MEM in the well. 


\subsubsection{Biochemical Analysis of DNA Quantity in AL Sponge Scaffolds after Subculture}

The scaffolds taken from culture medium after 3 weeks of subculture were washed two times in PBS $(-)$ and frozen at $-80^{\circ} \mathrm{C}$. They were then crushed and homogenized in $0.5 \mathrm{ml}$ of a 10 -fold concentration of TNE buffer solution ( $\mathrm{pH} 7.4 ; 10 \mathrm{mmol}$ Tris-HCl, $1 \mathrm{mmol}$ EDTA and $100 \mathrm{mmol} \mathrm{NaCl}$ ) using a Mixer Mill ${ }^{\circledR}$ (MM301; Verder Scientific Co., Ltd., Tokyo, Japan). The homogenized samples were ultra-sonicated for 20 minutes two times in 10-minute intervals at $3^{\circ} \mathrm{C}$ (BIORUPTOR ${ }^{\circledR}$ UCW-201; Tosho Denki Co., Ltd., Yokohama, Japan). For quantitative analysis of DNA in the scaffolds, $20 \mu$ of the sonicated suspension was mixed with $200 \mu \mathrm{l}$ of Hoechst 33258 (FUJIFILM Wako Pure Chemical Corp.) at $2.5 \mu \mathrm{g} / \mathrm{ml}$. Salmon sperm DNA (FUJIFILM Wako Pure Chemical Corp.) was used as the standard. DNA was measured using a fluorescence-spectrum photometer (Spectra-Max ${ }^{\circledR}$ M5; Molecular Devices, Inc., CA, USA) at an excitation wavelength of $355 \mathrm{~nm}$ and fluorescence emission at $460 \mathrm{~nm}$.

\subsubsection{Biochemical Analysis of ALP Quantity in AL Sponge Scaffolds after Subculture}

The ALP in the scaffolds was measured biochemically using a commercially available kit for measurement of alkaline phosphatase activity (LabAssay ALP ${ }^{\circledR}$ : FUJIFILM Wako Pure Chemical Corp.). The methods for measuring the quantity of ALP in the scaffold using the kit are described below.

The remaining emulsion used for measurement of DNA was utilized for quantitative analysis of ALP. Each sample was centrifuged for 1 minute at $15,000 \times \mathrm{g}$. The $20 \mu \mathrm{l}$ of supernatant was reacted at $37^{\circ} \mathrm{C}$ for 15 minutes with $100 \mu \mathrm{l}$ of carbonate buffer solution ( $\mathrm{pH} 9.8$ ) containing $p$-nitro-phenylphosphate as a substrate after mixing for 1 minute. Then, the reaction was stopped by adding $80 \mu \mathrm{l}$ of $0.2 \mathrm{~mol} / \mathrm{l}$ sodium hydroxide solution and mixing for 1 minute. Absorbance of the reactant was measured at $405 \mathrm{~nm}$. The value of ALP was represented as $\mu \mathrm{mol}$ of $p$-nitrophenol released after 30 minutes of incubation at $37^{\circ} \mathrm{C}$.

\subsubsection{Immunochemical Analysis of OC in the AL Sponge Scaffold after Subculture}

After the subculture for 3 weeks, each culture medium in which the scaffolds were immersed was immunochemically corrected for quantitative analysis of OC. Supernatants in each well of culture medium were transferred to a 2-ml microtube. The immunochemical quantitative analysis of OC was performed to estimate osteogenesis in the scaffold by rBMCs. Rat-MID ${ }^{\mathrm{TM}}$ Osteocalcin ELISA (Immunodiagnostic System Ltd., MD, USA) was used in this analysis. The procedure is described below.

The assay was performed at room temperature. All samples were tested in duplicate. Biotinylated synthetic OC was added to each streptavidin pre-coated well and incubated for 30 minutes on a microtiter plate mixing apparatus. The wells were washed three times. A monoclonal antibody specific against the mid-molecular part of OC and PBS buffer for dilution were mixed in a microtube at a volume ratio of 1 : 100. In the streptavidin pre-coated wells, $150 \mu \mathrm{l}$ of the monoclonal antibody was previously pipetted. In the wells, $20 \mu \mathrm{l}$ of standard solution, control or specimen was added and mixed for 60 minutes. After washing the wells, $100 \mu \mathrm{l}$ of the peroxidase-conjugated mouse IgG antibody was added to each well and incubated with mixing for 60 minutes. The wells were washed three times. One hundred microliters of a tetramethylbenzidine solution as a chromogenic substrate was pipetted into each well and incubated for 15 minutes in the dark with mixing. The chromogenic reaction in each well was stopped by adding $100 \mu \mathrm{l}$ of $0.18 \mathrm{~mol}$ sulfuric acid. The absorbance was measured at $450 \mathrm{~nm}$ using a spectrophotometer (SpectraMax ${ }^{\circledR}$ M5).

\subsection{In Vivo Hard Tissue Formation by rBMCs in AL Sponge Scaffolds}

\subsubsection{AL Sponge Scaffolds}

For the in vivo experiments, 4\%AL Sponge, 10\%AL Sponge and 10\%Chs-10\%AL Sponge were used. These AL sponges were expected to be compressed and flattened in the subcutis due to their weak structure. Therefore, cylindrical porous hydroxyapatite (HA; Hoya Technosurgical Company, Tokyo, Japan) with a hollow center was applied as a shell to maintain the shape of the sponge in the dorsal subcutis of experimental animals. The HA was $10 \mathrm{~mm}$ in height, $8 \mathrm{~mm}$ in outer diameter and the hollow center was 5 $\mathrm{mm}$ in diameter. The total porosity of the structures was $55 \%$. The diameter of each aperture on the surface of the HA structure and the pore size were both approximately $100-300 \mu \mathrm{m}$. The AL sponge was 
inserted into the hollow center of the HA.

\subsection{2. rBMC Seeding in AL Sponge Scaffolds}

A cell suspension with a concentration of $1 \times 10^{7}$ cells $/ \mathrm{ml}$ was prepared. In 4\%AL Sponge, 10\%AL Sponge and 10\%Chs-10\%AL Sponge, in order to seed $2 \times 10^{6}$ of rBMCs in the scaffold, $200 \mu$ of the cell suspension was dropped onto each AL sponge. Nine sponges from each group of $4 \% \mathrm{AL}, 10 \% \mathrm{AL}$ and $10 \%$ Chs-10\%AL sponge were used for implantation after seeding of rBMCs. Six of nine sponges after subcutaneous implantation were used for biochemical and immunochemical analysis and the remaining three were used for histological examination. To adhere rBMCs on the wall of the pores of the AL sponges, the sponges were incubated at $37^{\circ} \mathrm{C}$ in $5 \% \mathrm{CO}_{2}$ and $95 \%$ relative humidity for 1 hour. Then, the sponges were immersed in $2 \mathrm{ml}$ of MEM and incubated for a day in an incubator at $37^{\circ} \mathrm{C}$ in $5 \% \mathrm{CO}_{2}$ and $95 \%$ relative humidity.

\subsubsection{Implantation of the AL Sponge Scaffolds in the Dorsal Subcutis of Rats}

Under general anesthesia by inhalation of isoflurane, the back of the syngeneic rats was shaved and disinfected with povidone iodine solution (POVIDONE-IODINE SOLUTION 10\% [MEIJI] ${ }^{\circledR}$; Meiji Seika Pharma Co., Ltd., Tokyo, Japan). On the back along the spinal column, subcutaneous pockets were incised. One pocket was on the right side and two were on the left side. Incisions for the pockets after insertion of a scaffold in each pocket were sutured using a skin stapler (Precise ${ }^{\mathrm{TM}}$ skin stapler; $3 \mathrm{M}$ Japan Limited, Tokyo, Japan) and covered with adhesive (Aron Alpha ${ }^{\circledR}$; Toagosei Co., Ltd., Tokyo, Japan).

\subsubsection{Evaluation of Bone Formation in the Pores of Implanted AL Sponge Scaffolds}

Osteogenesis in the scaffolds was estimated biochemically, immunochemically and histologically. Eight weeks after dorsal subcutaneous implantation of the scaffolds, the rats were euthanized by excessive inhalation of isoflurane. The implanted scaffolds with the surrounding connective tissue were resected from the dorsal subcutis.

\subsection{Biochemical Measurement of the ALP Level in AL Sponge Scaffolds and Immunochemical Measurement of OC Quantity in AL Sponge Scaffolds}

After removal of the scaffolds from the subcutis of rats, the surrounding connective tissue was removed from the surface of three of nine scaffolds as much as possible. They were immediately frozen at $-80^{\circ} \mathrm{C}$. Then, they were crushed and homogenized in $0.5 \mathrm{ml}$ of a 10 -fold concentration of TNE buffer solution (pH7.4; $10 \mathrm{mmol}$ Tris- $\mathrm{HCl}, 1 \mathrm{mmol}$ EDTA, $100 \mathrm{mmol} \mathrm{NaCl}$ ) containing $50 \mu \mathrm{l}$ of surface active agent (TWEEN $^{\circledR}$ 20; 10\% concentration: Sigma-Aldrich) using a Mixer Mill ${ }^{\circledR}$ (MM 301; Verder Scientific Co., Ltd., Tokyo, Japan). The homogenized samples were sonicated two times for 30 seconds in 10-second intervals with supersonic waves using BIORUPTOR ${ }^{\circledR}$ (UCW-201; Tosho Denki Co., Ltd., Yokohama, Japan) to collapse the cell bodies.

Then, each sample was centrifuged for 1 minute at 15,000 $\times \mathrm{g}$. The quantity of ALP in the scaffolds was measured biochemically. ALP activity was assayed as the release of $p$-nitrophenol from p-nitrophenylphosphate, $\mathrm{pH} 9.8$, and the $p$-nitrophenol release was monitored by optical density at 405 nm using LabAssay ALP $^{\circledR}$. The value of ALP activity was presented per scaffold as $\mu$ mol of $p$-nitrophenol released after 30 minutes of incubation at $37^{\circ} \mathrm{C}$. Absorbance was measured using a spectrophotometer.

After quantitative analysis of ALP, in order to separate OC from HA, $5 \mathrm{ml}$ of $20 \%$ formic acid was added to the precipitate and decalcified at $3^{\circ} \mathrm{C}$ for 1 week. Then, to collect the OC adhered to the HA, a total of $500 \mu \mathrm{l}$ of demineralized sample and buffer was centrifuged for 5 minutes at $14,000 \times \mathrm{g}$ using an ultrafiltration spin column (APRO Science Inc., Tokushima, Japan). This process was repeated three times. OC was quantified immunochemically using Rat-MID ${ }^{\mathrm{TM}}$ Osteocalcin ELISA (Immunodiagnostic Systems Ltd., AZ, USA). In brief, the procedure was as follows: The desalted supernatants were poured into each well of a 96-well micro-plate. The bottom of each well was coated with anti-rat OC antibody. Peroxidase-conjugated anti-rat OC polyclonal antibody was added to each well. An equivalent mixture of peroxidase substrate and hydrogen peroxide water was added, followed by incubation in the dark. Absor- 
bance at $450 \mathrm{~nm}$ was measured using a spectrophotometer.

Data are presented as the mean \pm standard deviation. Statistical comparisons between the mean values in implanted scaffolds were performed using two-way unrepeated ANOVA followed by post hoc analysis using the Tukey-Kramer's test. Differences of $p<0.01$ were considered significant.

\subsection{Histological Examination of Bone Formation in Implanted AL Sponge Scaffolds}

The remaining three scaffolds were used for histological evaluation. The implanted sponges taken out from the subcutaneous tissue were fixed for 48 hours in $10 \%$ neutral buffered formalin solution (FUJIFILM Wako Pure Chemical Corp.). Decalcification of implanted sponges was performed in $10 \%$ formic acid solution for 3 weeks followed by dehydration in absolute ethanol. They were permeated with xylene for embedding in paraffin. The paraffin-embedded specimens were serially cut into $9-\mu \mathrm{m}$-thick sections. These serial sections were alternately stained with hematoxylin-eosin for histological examination under an optical microscope.

\section{RESULTS}

\subsection{Microstructural Observation of Prepared AL Sponge Scaffolds by SEM}

By lyophilization, 4\%AL Sponge, 8\%AL Sponge, 10\%AL Sponge, 1\%Chs-10\%AL Sponge and $10 \%$ Chs-10\%AL Sponge were made. Then, the internal microstructure of each sponge by SEM was observed. Representative SEM images of each type of sponge scaffold are shown in Figures 1(a)-(e).

The major axis of the $4 \% \mathrm{AL}$ Sponge was approximately $30 \mu \mathrm{m}$ to $250 \mu \mathrm{m}$ (Figure 1(a)). The pore size was small. The average pore size was approximately $100 \mu \mathrm{m}$. SEM observation at higher magnification revealed mutual connection with the apertures. Most of the interconnected pores of the 4\%AL Sponge were approximately $50 \mu \mathrm{m} \times 150 \mu \mathrm{m}$ or smaller. These pores did not accurately exhibit a honeycomb configuration. Apertures between adjacent pores were noted. The diameter of apertures ranged from approximately $30 \mu \mathrm{m}$ to $150 \mu \mathrm{m}$.

A representative SEM image of the $8 \%$ AL Sponge made from $8 \%$ alginate gel by freeze drying is presented in Figure 1(b). Micropores in the sponge were mutually connected with neighboring ones by one or several apertures. The pores inside the 8\%AL Sponge on the major axis ranged in size from approximately $300 \mu \mathrm{m}$ to $750 \mu \mathrm{m}$. The diameter of apertures ranged from approximately $200 \mu \mathrm{m}$ to $600 \mu \mathrm{m}$. The shape of each connected pore was not honeycomb.

The internal microstructure of the sponge made by lyophilization of $10 \%$ alginate gel was observed with SEM. A representative image is shown in Figure 1(c). The sizes of internal pores were fairly large compared with those in the 4\%AL Sponge. The pore sizes found in the cross-section on the long axis of the sponge were approximately $800 \mu \mathrm{m}$ or larger. However, no pores were $1 \mathrm{~mm}$ or larger. There was no significant difference in the length of the major axis of each pore. A honeycomb structure was not observed.

A representative SEM image of the $1 \%$ Chs-10\%AL Sponge made by adding $1 \%$ Chs to the $10 \%$ AL gel is presented in Figure 1(d). The inner pore surface was not lubricious, but it appeared as a rough surface. This may be a feature of the stomatal wall surface of sponges made from a gel including Chs. The properties of the inner surface of the pores were different from those of sponges not containing Chs. The pore sizes ranged from $100 \mu \mathrm{m}$ to $1000 \mu \mathrm{m}$.

A cross-section of the 10\%Chs-10\%AL Sponge on SEM is shown in Figure 1(e). The major axis of each pore ranged from $300 \mu \mathrm{m}$ to $900 \mu \mathrm{m}$, with an average of approximately $700 \mu \mathrm{m}$. The inner pore surface was rough. A honeycomb structure was not observed in the sponges.

\subsection{In Vitro Measurement of Alkaline Phosphatase and OC during Hard Tissue Formation in AL Sponge Scaffolds by rBMCs}

\subsubsection{Biochemical Analysis of ALP Quantity and Activity in AL Sponge Scaffolds}

The amount of ALP in AL sponge scaffolds is presented in Figure 2(a). The amount of ALP in the 
$10 \% A L$ Sponge was $0.444 \pm 0.022 \mathrm{mmol} / \mathrm{scaffold}$. The ALP level in the $4 \% \mathrm{AL}$ Sponge was $0.373 \pm 0.029$ $\mathrm{mmol} / \mathrm{scaffold}$ and the amount in the $8 \% \mathrm{AL}$ Sponge was $0.374 \pm 0.007 \mathrm{mmol} / \mathrm{scaffold}$. A significant difference was observed among sponges $(p<0.01)$. The average value in the $10 \% \mathrm{Chs}-10 \% \mathrm{AL}$ Sponge was the highest among the three types of sponge scaffolds at $0.459 \mathrm{mmol} / \mathrm{scaffold}$. There was no significant difference between the 10\%AL Sponge and the Chs-10\%AL Sponge. The ALP amount was slightly lower in the $1 \%$ Chs-10\%AL Sponge.

The amount of DNA in each scaffold was measured (Figure 2(b)). The DNA concentration in each sponge scaffold was 31 to $36 \mu \mathrm{g} / \mathrm{ml}$. The $4 \% \mathrm{AL}$ and $10 \% \mathrm{Chs}-10 \% \mathrm{AL}$ Sponges had slightly significant different DNA concentrations from the $8 \%$ and $10 \%$ AL Sponges $(p<0.01)$. The average DNA amount was highest in the 4\%AL Sponge and significantly different from that in the $10 \% \mathrm{Chs}-10 \% \mathrm{AL}$ Sponge. The amount of DNA in the 10\%Chs-10\%AL Sponge was significantly low.

The amount of ALP in each scaffold was divided by the DNA amount in each scaffold. In Figure 2(c),

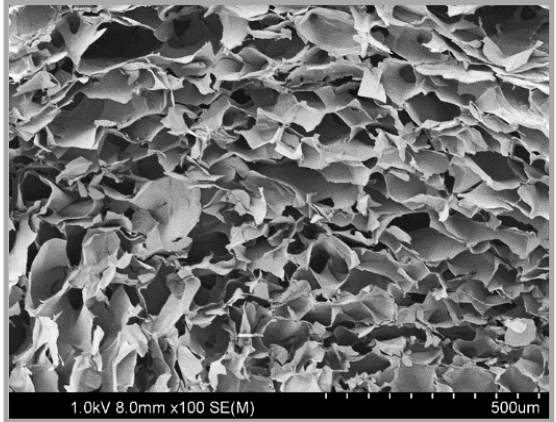

(a)

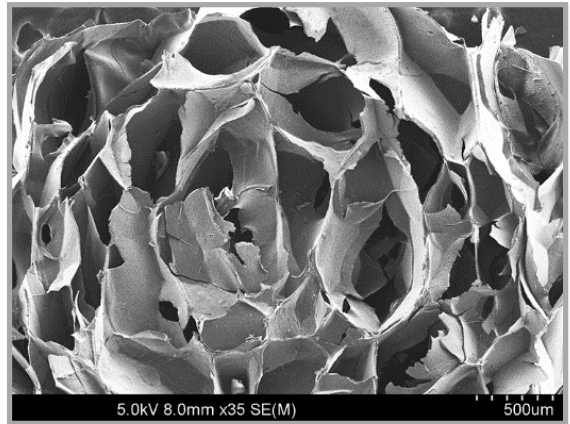

(d)

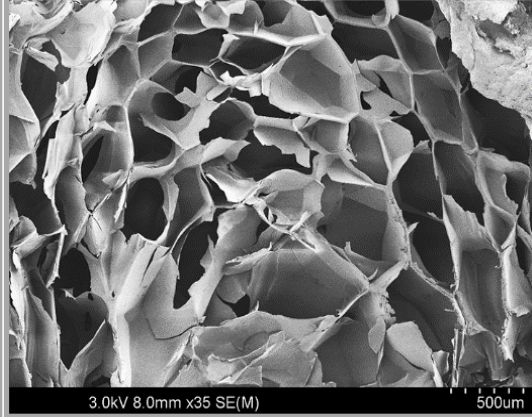

(b)

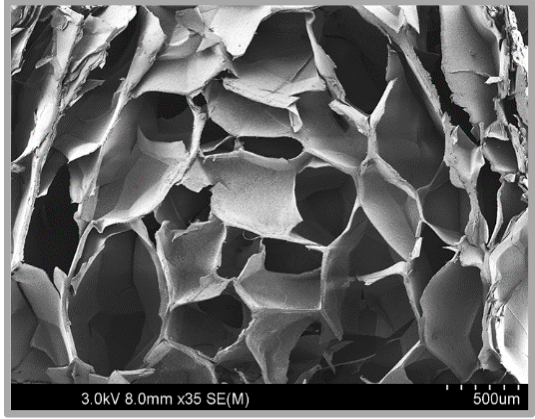

(c)

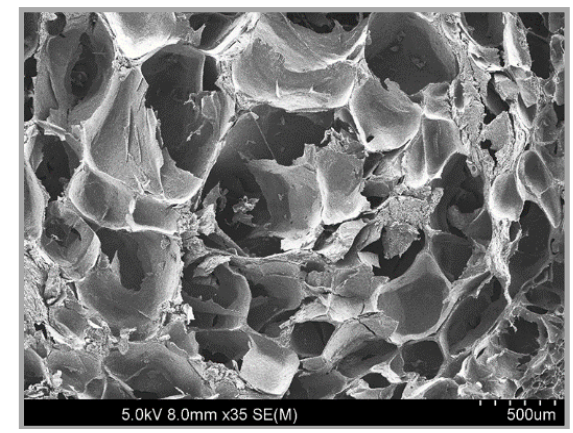

(e)

Figure 1. (a) A representative scanning electron microscope (SEM) image of the 4\%AL Sponge. Pores mutually connected with neighboring ones were observed. Most pores in the 4\%AL Sponge were generally small. (Bar: $500 \mu \mathrm{m}$ ). (b) A representative SEM image of the 8\%AL Sponge. Pores mutually connected with neighboring ones. Interconnected apertures were noted. No perfect honeycomb-shaped pores were observed. (Bar: $500 \mu \mathrm{m}$ ). (c) A representative SEM image of the 10\%AL Sponge. Most of the pores seemed to be interconnected. The shape in the cross-section formed by the mutually adjacent pores was not a typical honeycomb structure. The wall surface of each pore was smooth. (Bar: $500 \mu \mathrm{m}$ ). (d) A representative SEM image of the 1\%Chs-10\%AL Sponge. The inner surface of the pore appeared rough. The length of the major axis of each pore was somewhat irregular. (Bar: $500 \mu \mathrm{m})$. (e) A representative SEM image of the $10 \% \mathrm{Chs}-10 \%$ AL Sponge. The pores were slightly small. The surface of the pore wall was coarse and rough. Several pores with no aperture between adjacent pores were observed. (Bar: $500 \mu \mathrm{m}$ ). 


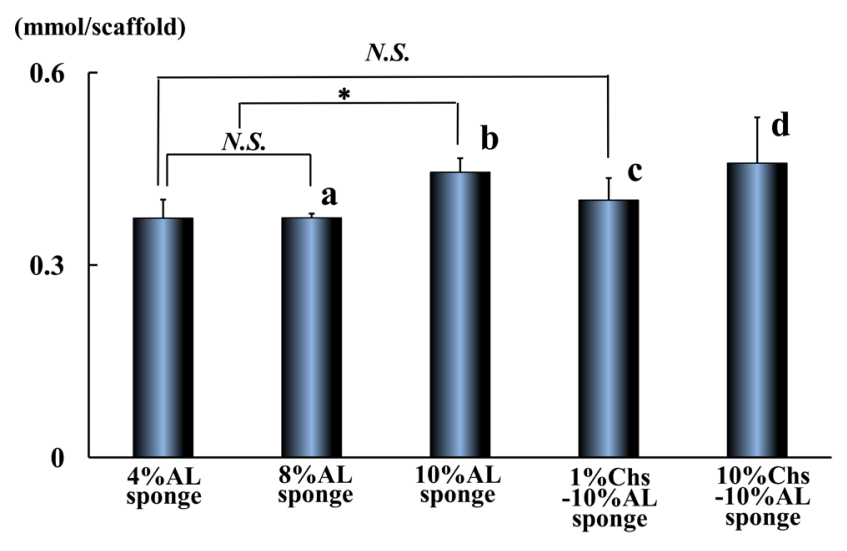

(b, c and d: N.S., a: $p<0.01$ v.s. d, $*: p<0.01$, N.S.: No significant )

(a)

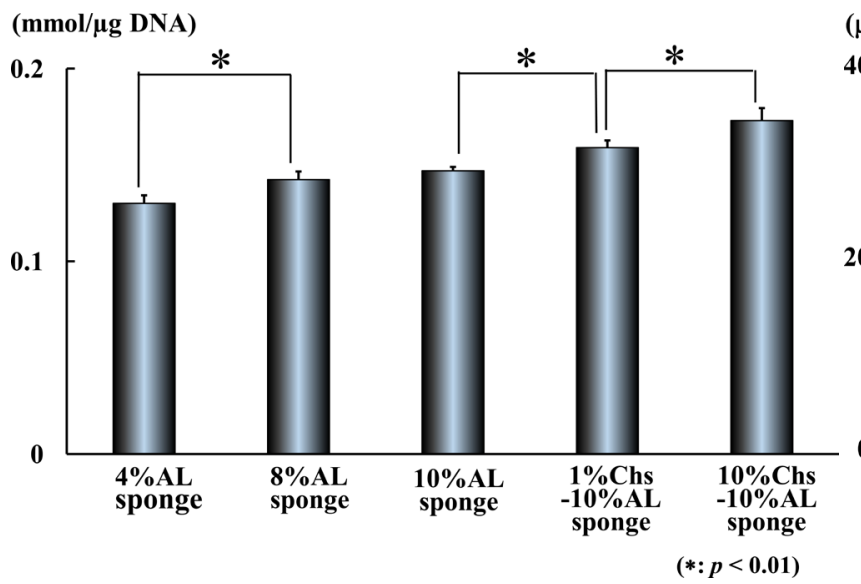

(c)

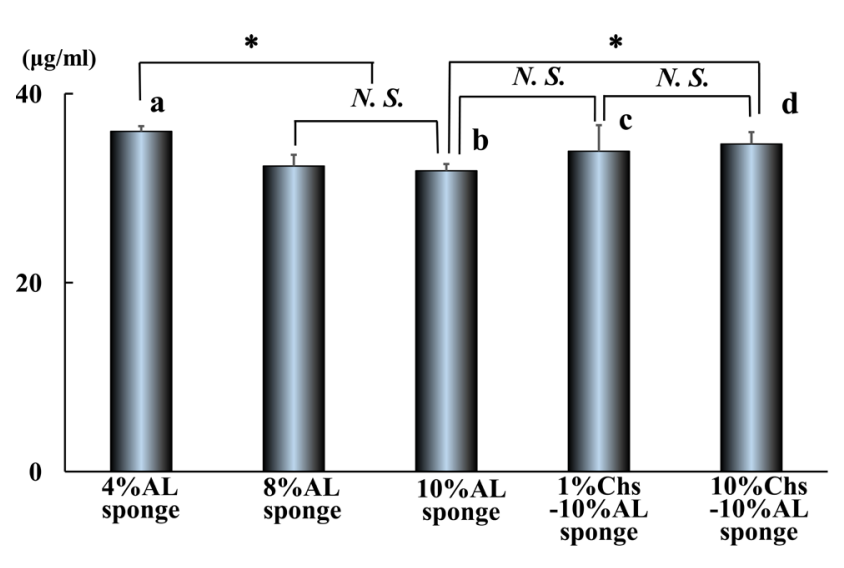

(b)

$(\mu \mathrm{g} / \mathrm{ml})$

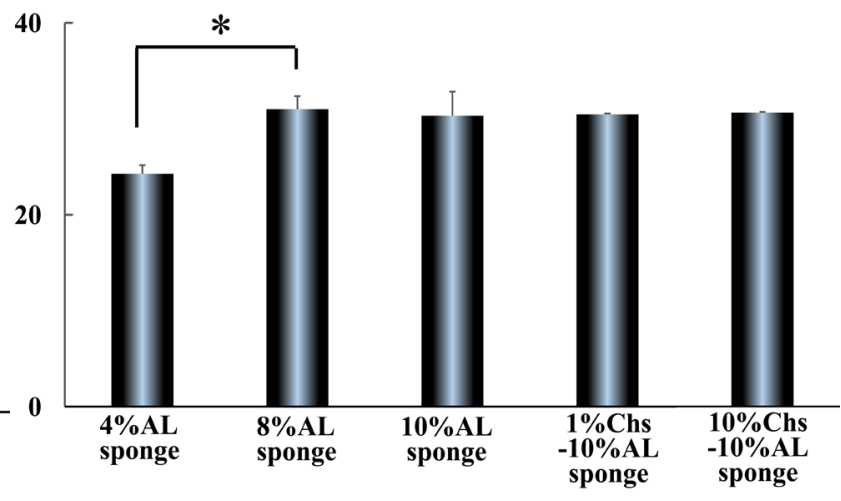

$(*: p<0.01)$

(d)

Figure 2. (a) Amount of ALP (alkaline phosphatase) in AL Sponges and Chs-AL Sponges in vitro. There was no significant difference between $4 \% \mathrm{AL}$ and $8 \% \mathrm{AL}$ Sponges. The $10 \% \mathrm{AL}$ Sponge had a significantly higher ALP amount. The ALP amount in the 4\%AL and 8\%AL Sponges was not significantly different from that in the $1 \%$ Chs-10\%AL Sponges. (a: $p<0.01$ v.s. d, $*: p<0.01$, N.S.: No significant, $\mathrm{n}=6$ ) (b) Amount of DNA (deoxyribonucleic acid) in AL sponges and Chs-AL Sponges in vitro. There was no large quantitative difference in the average DNA amount. There was no significant difference between the 4\%AL Sponge and 1\%Chs-10\%AL Sponge. There was also no significant difference between the $1 \%$ Chs-10\%AL Sponge and the $10 \%$ Chs-10\%AL Sponge. $(p<0.01, \mathrm{n}=$ 6). (c) Level of ALP activity in AL sponges and Chs-AL Sponges in vitro. The level of ALP activity in the $4 \% A L$ Sponge was significantly low. The ALP activity in the $10 \% \mathrm{Chs}-10 \% \mathrm{AL}$ Sponge was significantly high. $(p<0.01, \mathrm{n}=6, *: p<0.01)$. (d) Amount of osteocalcin (OC) in AL sponges and Chs-AL Sponges in vitro. The amount of OC in the $4 \% \mathrm{AL}$ Sponge was low. There was a significant difference among the amount of OC in other sponges. The amount of OC in the 8\%AL and $10 \% \mathrm{AL}$ Sponges was not significantly different from that in sponges containing Chs. $(p<0.01, \mathrm{n}=6)$.

the results are shown as the ALP activity level. The activity of the $4 \%$ AL Sponge was $0.13 \pm 0.0042 \mathrm{nmol} / \mu \mathrm{g}$ DNA. The ALP activity observed in $8 \%$ and $10 \%$ AL Sponges was significantly higher. There was no significant difference between the $8 \%$ AL Sponge and the 10\%AL Sponge in the level of ALP activity. There is a significant difference in the level of ALP activity between the $1 \%$ Chs- $10 \% \mathrm{AL}$ Sponge and the 
10\%Chs-10\%AL Sponge. The ALP activity in Chs-AL Sponges was significantly higher. The ALP activity in the $10 \%$ Chs $-10 \%$ AL Sponge was $0.173 \mathrm{nmol} / \mu \mathrm{g}$ DNA. ALP activity in the sponges was enhanced by Chs.

\subsubsection{Immunochemical Analysis of OC in AL Sponge Scaffolds}

The $8 \% A L$ Sponge had the highest average OC amount at $31.01 \mu \mathrm{g} / \mathrm{ml}$. The OC amount in the $4 \% \mathrm{AL}$ Sponge was significantly lower than that in the other four sponge scaffolds. The amount of OC in the $4 \%$ AL Sponge was $24.26 \pm 0.91 \mu \mathrm{g} / \mathrm{ml}$. The OC amount in the other four sponge scaffolds ranged from 30.3 to $30.5 \mu \mathrm{g} / \mathrm{ml}$. There was no significant difference in the amount of OC among the other four sponges. The OC amount in each sponge scaffold and the differences among them are presented in Figure 2(d).

\subsection{In vivo Hard Tissue Formation by rBMCs in AL Sponge Scaffolds}

\subsubsection{Biochemical Measurement of ALP Level and Immunochemical Measurement of OC Quantity in AL Sponge Scaffolds}

The ALP amount in each sponge after subcutaneous implantation for 8 weeks is shown in Figure 3(a) $(\mathrm{n}=6, p<0.01)$.

The concentration of the gel markedly affected the amount of ALP in vivo. In particular, the amount of ALP was large in sponges made from 10\% AL gel. The ALP amount per scaffold of the 4\%AL Sponge was $2.7 \pm 0.3 \mathrm{mmol}$. On the other hand, the ALP amount per scaffold of the 10\%AL Sponge was $5.6 \pm 1.1$ mmol. There was a significant difference in the amount of ALP after subcutaneous implantation between the $4 \% A L$ Sponge and the 10\%AL Sponge. There was no significant difference in the amount of ALP after subcutaneous implantation between the $4 \% A L$ Sponge and the $8 \% A L$ Sponge $(2.7 \pm 1.5 \mathrm{mmol})$. The amount of ALP in the 10\%AL Sponge was high. There was a significant difference in ALP amount between $10 \%$ AL Sponge and the other sponges. There was more ALP in the $10 \%$ Chs- $10 \%$ AL Sponge than in the $1 \%$ Chs-10\%AL Sponge. The ALP amount in the 1\%Chs-10\%AL Sponge was $2.5 \pm 0.3 \mathrm{mmol}$ per scaffold, which was significantly lower.

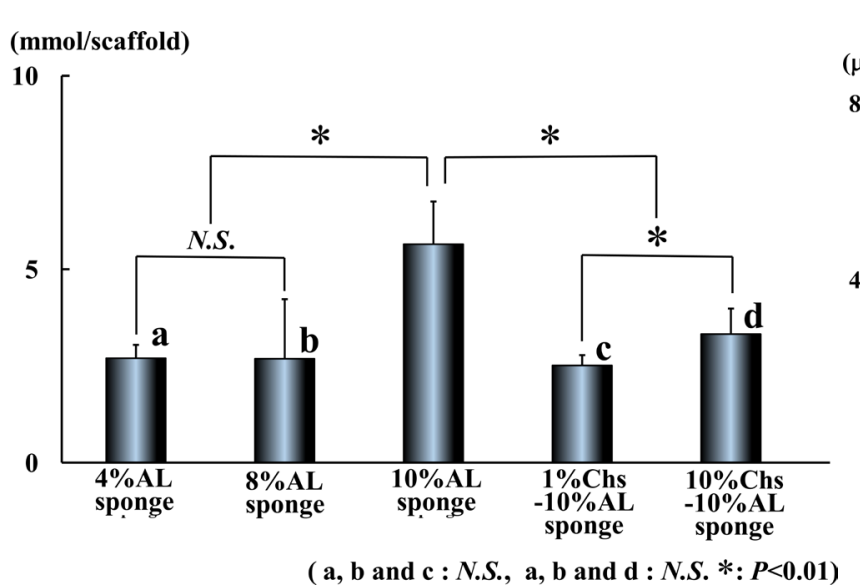

(a)

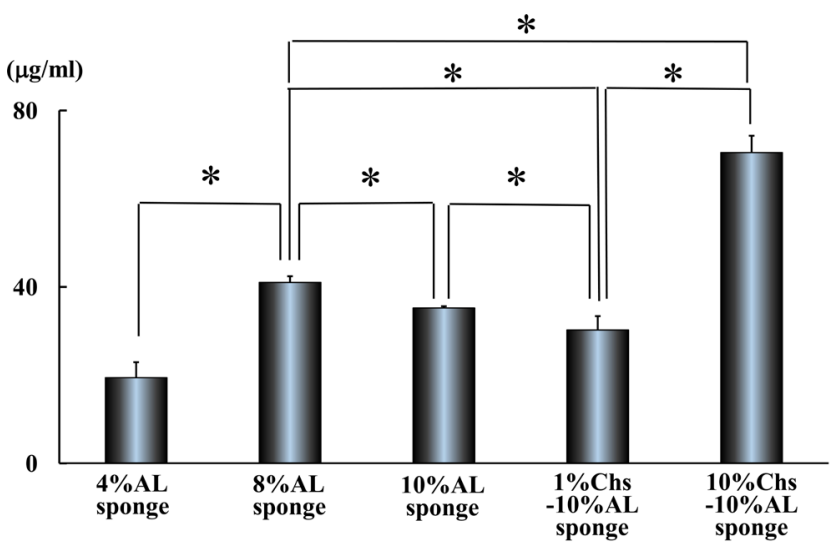

(b)

Figure 3. (a) Amount of ALP in AL sponges and Chs-AL Sponges in vivo. There was a marked amount of ALP in the 10\%AL Sponges. The amount of ALP in the control HA scaffold was significantly lower. There was no significant difference among the other sponges. $(p<0.01, \mathrm{n}=6)$. (b) Amount of OC in AL sponges and Chs-AL Sponges in vivo. The small amount of OC in the 4\%AL Sponge was notable. The OC amount in the $8 \% \mathrm{AL}$ Sponge was significantly greater than that in the $10 \% \mathrm{AL}$ and $1 \% \mathrm{Chs}-10 \% \mathrm{AL}$ Sponges. However, the large amount of OC in the $10 \% \mathrm{Chs}-10 \% \mathrm{AL}$ Sponge significantly differed from than in the other sponges. $(p<0.01, \mathrm{n}=6)$. 
The amount of $\mathrm{OC}$ in each sponge after subcutaneous implantation is shown in Figure 3(b) $(\mathrm{n}=6, p$ $<0.01$ ). The OC amount in the $10 \%$ Chs $10 \% A L$ Sponge was the highest at $70.4 \pm 3.8 \mu \mathrm{g} / \mathrm{ml}$, which was significantly different from that in the other sponges. The amount of OC in each scaffold was $19.4 \pm 3.5$ $\mu \mathrm{g} / \mathrm{ml}$ for the $4 \% A L$ Sponge, $4.1 \pm 1.4 \mu \mathrm{g} / \mathrm{ml}$ for the $8 \% A L$ Sponge and $35.2 \pm 0.4 \mu \mathrm{g} / \mathrm{ml}$ for the $10 \% \mathrm{AL}$ Sponge. The OC amounts varied significantly. The amount of OC in the $1 \%$ Chs-10\%AL Sponge was $30.2 \pm$ $3.1 \mu \mathrm{g} / \mathrm{ml}$. There was a significant difference in the OC amount between the two 10\%AL Sponges.

\subsection{Histological Evaluation of Bone Formation in Implanted AL Sponge Scaffolds}

A representative optical microscope image of a subcutaneously implanted 10\%AL Sponge at 8 weeks post-operation is shown in Figure 4(a). With the 10\%AL Sponge as a scaffold, the pores in the interior space were extremely narrow. Connective tissue, including small blood vessels, was observed in the narrow space, and newly formed bone was confirmed. However, the amount of bone formed in the scaffold was insufficient to fill all of the pores.

Representative histological findings of the 10\%Chs-10\%AL Sponge scaffold that was removed from the subcutaneous tissue 8 weeks after implantation are presented in Figure 4(b). New bone was clearly observed in the structure of the sponge as a scaffold. Bone was formed in relatively narrow areas, which were considered to be pores in the sponge.

\section{DISCUSSION}

Stem cells, scaffolds and growth factors are important elements in bone tissue regeneration [26]. Furthermore, the geometric characteristics of scaffolds are considered to play an important role in osteoinduction [27]. As teeth and bones are three-dimensional structures, hydroxyapatite with high crystallinity can be seen on tooth surfaces. Bone consists of amorphous calcium phosphate and considerably low crystallinity hydroxyapatite. Therefore, for the regeneration of a tooth or bone, application of a scaffold may be useful. In in vivo and in vitro studies on osteogenesis, HA has been commonly used as a scaffold with and without other factors [28-34]. HA has excellent osteoinductivity and biocompatibility, and amino

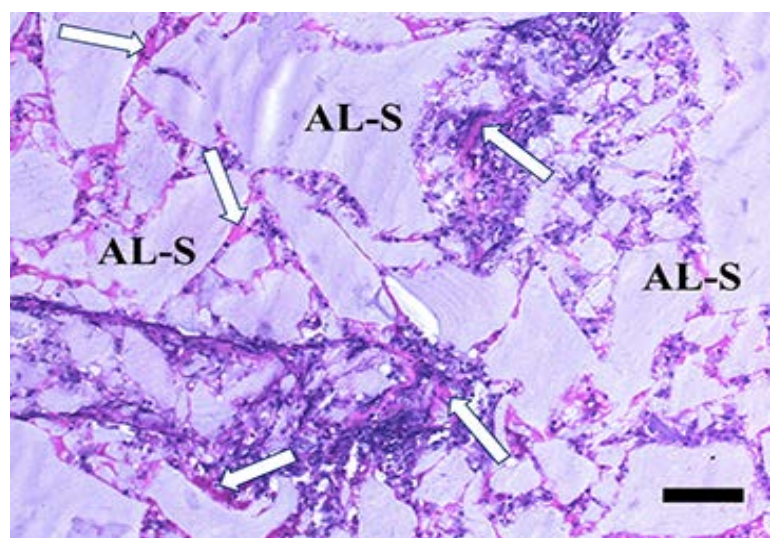

(a)

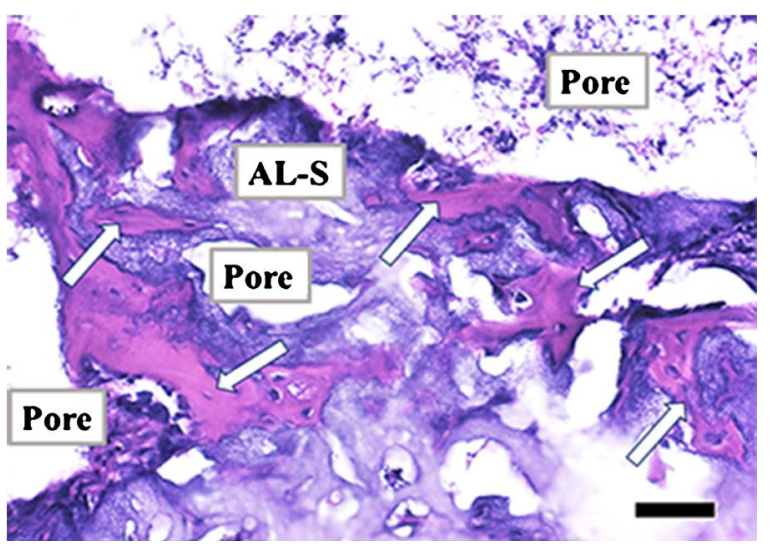

(b)

Figure 4. (a) A representative optical microscope image of a subcutaneously implanted $10 \% \mathrm{AL}$ Sponge (AL-S): 8 weeks postoperative. Connective tissue and small blood vessels infiltrated the narrow sponge structures, and newly formed bone tissue (Arrow) was observed. (Bar: $100 \mu \mathrm{m})$. (b) A representative optical microscope image of a subcutaneously implanted 10\%Chs-10\%AL Sponge (AL-S): 8 weeks postoperative. Infiltration of connective tissue and small blood vessels into the sponge structure was limited. However, newly formed bone tissue (Arrow) was observed within the microstructure of the sponge. (Bar: $100 \mu \mathrm{m}$ ) Pore: Pore in the sponge. 
acids and proteins adhere well to HA. The use of scaffolds or three-dimensional culture of stem cells is considered essential for regeneration. The scaffolds should be devised such that the shape and the size of the pores are optimal for osteogenesis [35]. In an in vivo study, Damien et al. previously reported that cylindrical HA scaffolds with pore sizes of $400-600 \mu \mathrm{m}$ and $80 \%$ porosity were suitable for the repair of femoral defects in rats [36]. For optimum bone regeneration, it was reported that a minimum pore size of $200-400 \mu \mathrm{m}$ would be necessary for inducing sufficient vascularization, osteoconduction and formation of mineralized tissue within the scaffold [28]. Moreover, pore sizes ranging from 150 to $500 \mu \mathrm{m}$ favor osteoconduction in the scaffolds [28, 37]. Zhang et al. found that a hydroxyapatite scaffold with excellent osteoconductivity had pores of which sizes were ranged from $50 \mu \mathrm{m}$ to $200 \mu \mathrm{m}$ for cell infiltration and bone ingrowth [38]. Zdravkov et al. classified the most frequently used pore sizes as macro-, meso-, micro-, super-micro-, ultra-micro- and sub-micro-pores [39].

There are many reports in which collagen [40] or gelatin [41] sponges were used as a scaffold, and AL hydrogel or AL sponge scaffold have been widely used. Although sponges made from AL gel without other components are likely to be structurally or physically fragile as a scaffold, they have superior biocompatibility and biodegradability. AL gel was previously reported to have fluidity at concentrations lower than $4 \%$ [19]. The porous AL sponge was prepared via the freeze-drying method [42]. Collapse caused by lyophilization was observed in the structure of many sponges made from low concentrations of AL in this study. From the results, it was considered that the gel concentration of AL should be over $4 \%$ to avoid collapse during freeze drying of the gel. Concentrations of AL gel greater than $8 \%$ were suggested to be required to make sponges without structural destruction by lyophilization. Most of the sponges made from $10 \%$ AL gel did not collapse structurally during formation and had a stable structure. On in vitro examination of bone formation by rBMCs using the sponges, the 10\%AL Sponge had the highest ALP activity and amount of OC. The 10\%AL Sponge was suggested to have superior osteogenesis promoting ability. The rBMCs may have attached well to the pore walls. The pore sizes of the AL sponges prepared and used in this study ranged from $350-500 \mu \mathrm{m}$. Based on previous reports, the pore sizes of the scaffolds in this study were sufficient for inducing osteogenesis by rBMCs. The pore sizes of $10 \%$ AL Sponges were more suitable for bone formation when comparing different concentrations of AL gel. The pores in the sponges made from low concentrations of AL gel may have been inappropriate in size and shape for bone formation. As the shape and sizes of the pores of AL sponges were unable to be controlled in this study, the pore sizes were only different due to the concentration of AL in the gel. A mechanically stable AL sponge may be prepared by lyophilization of an appropriate concentration of AL gel. The pores of the AL sponge scaffolds in this experiment, which were made and used for experiments in vitro and in vivo, were mutually connected with apertures but did not have a well-ordered honeycomb construction. In the future, the technique to constitute a honeycomb construction to the sponge must be established.

Based on OC amount in the AL sponge measured immunochemically in this in vivo and in vitro studies, bone formation was poor in the 4\%AL Sponge. Differences in the consistency of the gel may have led to variances in pore size depending on the concentration of AL. There was a time interval between injection of the gel into the metal ring and freezing. The $4 \% \mathrm{AL}$ gel had low viscosity and many bubbles were easily discharged from the gel. Large bubbles are released more quickly due to their buoyancy. The pore sizes of the AL sponges varied depending on the concentration of AL gel. During mixing of the gel, many air bubbles were contained in the gel. The relatively large air bubbles may have been released just after pouring the gel into the metal ring. Thus, only small bubbles retained in the gel should cause the formation of a number of small pores in the sponge scaffold. From these findings, it was considered that the sponges made from $4 \%$ AL gel might be unsuitable for the sponge. So, the sponges made from $4 \% \mathrm{AL}$ gel with Chs was not used in this study.

In this study, OC was measured in the AL sponges in vitro and in vivo, and osteogenesis was observed in the scaffolds by histological examination in vivo. It is desirable that all the pores in a scaffold be filled with bone. However, induction of bone into the all of pores in the scaffold was not achieved. The goal is to form bone in all of the pores and assimilate the scaffold into the surrounding hard tissue. Tissue engineering involves seeding cells in pores of a scaffold, followed by culturing in vitro prior to implantation of the 
scaffold in vivo. It is an essential role of the scaffold to provide an appropriate environment to make inoculated cells adhere to the pore wall of the scaffold [43]. Moreover, scaffolds should have suitable properties to promote the proliferation and differentiation of the cells. The wettability, softness and stiffness, roughness on the pore walls of a scaffold, and porosity, pore size, configuration of pores and interconnectivity of the pores of a scaffold significantly influence cell behavior such as adhesion, growth and differentiation $[44,45]$. The differentiation and adhesion capacity of stem cells is affected not only by chemical factors, but also by the physical properties of the substance in contact with the cells [46]. These factors have also been demonstrated to affect the bioactivity of scaffolds used for in vivo [47] regeneration of numerous tissues such as cartilage.

Chs involves in cell adhesion, proliferation, differentiation and mineralization [48-50]. Therefore, Chs may play a function in bone formation, and its activity is drawing attention. A small amount of Chs was included in the AL gel for the purpose of promoting proliferation and differentiation of stem cells, and forming bone in the sponges. It was previously reported that bone was induced by bone marrow cells in the pores of a sponge scaffold made from gel containing Chs and other chemical substances [51]. Bone had also been reconstructed in the periapical region by a porous ceramic cement scaffold with Chs [52]. Chs may directly affect adhesion on the cell surface. Cell adhesion is inhibited by removing cell surface Chs $[50,51]$. On the other hand, Chs may inhibit the differentiation of mesenchymal stem cells into hypertrophic chondrocytes. Negative charges due to a large amount of Chs inhibit the biological activity of growth factors and may inhibit the differentiation of stem cells [53]. According to this theory, the amount of Chs contained in the AL sponges used in this study was not excessive. It was reported in a previous in vivo study that, in the periapical region of rat mandibular molar root canals after pulp extirpation, cementum-like hard tissue was markedly induced by application of the combination of calcium phosphate and Chs [25]. The properties of the adhesive surface of the cells, the tension applied to the cells, and the ability of the cells to differentiate and adhere to the sponge scaffolds are likely related. Furthermore, the morphological properties of the surface for cell adhesion are involved in the differentiation and adhesion of stem cells to a scaffold. Many fine protrusions on the surface of the pore wall of $10 \% \mathrm{Chs}$-AL-Sponges were thought to be structures that allowed many cells to adhere well to the pore walls. Moreover, the cell adhesion and mineralization functions of Chs were considered to have enhanced the osteogenic potential of rBMCs in the scaffolds. There have been many reports of scaffolds made from numerous materials. Materials being used for implantation can be classified as bioinert, bioactive or biodegradable depending on the interaction of materials with the host tissue. Biomaterials that chemically interact with the host tissue are bioactive. Materials that are resorbed over time are biodegradable [54, 55]. AL sponges can be considered suitable as scaffolds because they are biodegradable [56]. However, nonabsorbent scaffolds with mechanical stiffness may be desirable in many cases. After repairing defective bone, a load is applied to the bone. The highly crystalline porous HA containing newly formed bone is sufficiently hard and can withstand loads. Ideally, bone is formed in the pores of HA and the scaffold is integrated with bone. No tissue interaction and a lower risk of adverse local or systemic effects may be advantages of bioinert materials as implant materials.

AL sponges were considered to be biodegradable scaffolds, but the sponges removed from the subcutis demonstrated less biodegradability during this experimental period. Bioactive materials often accumulate on ceramic and may strongly integrate. As a polycrystalline ceramic dissolves, and the extracellular concentrations of calcium and phosphate rise, a carbonate-apatite-crystal layer is precipitated on the ceramic [57]. This crystalline layer facilitates the bonding of native tissue to the biomaterial, which increases the strength of the bond between the tissue and scaffold [58]. However, it was considered that the AL sponges used in this study would exhibit physical weakness in the implanted subcutaneous tissue. Therefore, the sponges were inserted into the hollow center of the cylindrical HA in order to avoid the physical load from the surrounding environment. The AL sponge was not degraded during transplantation. Therefore, in this study, the phenomenon described in previous reports was not observed. Sponge scaffolds are considerably inferior to HA in physical strength. On the other hand, depending on the material, such sponge scaffolds can be easily deformed into any shape desired [40, 41]. In addition to collagen, calcium 
carbonate [59], synthetic polypeptide [60] and polylactic acid-polyglycolic acid copolymers [61] can be considered as suitable materials for sponge scaffold preparation for bone tissue regeneration. George et al. stated that scaffolds must be mechanically stable, biocompatible and resorbable, must permit cell adherence and proliferation, and be suitable for surgical implantation for tissue engineering [62]. AL gel presented excellent biocompatibility and biodegradability [18,63], and has been used as a scaffold for osteogenesis by three-dimensional culture of stem cells [64]. Previously, Kakigi et al. examined the possibility of osteogenesis by rBMCs in AL sponges in vitro, and found that $\mathrm{AL}$ gels at $2 \%$ or $4 \%$ containing calcium phosphate had low viscosity and were easy to prepare [19]. In this study, the sponges were made from 4,8 or $10 \%$ AL gel. High-concentration AL gel has a high viscosity. Excessive concentrations of AL solution may not be able to be kneaded to obtain a gel because of their high viscosity. In these sponges made from high-concentration gel, a larger amount of OC was made by rBMCs than in sponges made from lower concentration gel. This may have been because the sponge made from a high-concentration gel had a greater physical strength, and the pores became a place to attach or grow for cells.

Sponges implanted in the dorsal subcutaneous tissue may be compressed between epithelium and muscle. In the cage, the back of the animal may be pressed against floor or wall of the cage and the subcutaneously implanted AL sponges will be squashed by the load. The sponge contents containing rBMCs may be flow out into the surrounding tissue due to the pressure. In the squashed sponges, the space composed of pores should be very narrow for fiber tissue to infiltrate. The diameter of the pores would have become too small for the stem cells to maintain adhesion to the pore wall for osteogenesis. Therefore, HA scaffolds with a hollow center were used in combination. The HA had to prevent deformation of the sponge due to the pressure applied from the surrounding environment. Such protectors must be porous cylinders. If materials with a dense structure without pores are used, the tissue fluid may not permeate the AL sponge in the hollow center of the HA or circulate in the sponge. The biological reaction should have been transmitted through the pores of the HA to the AL sponge.

Previously, in vivo experiments using formalin-treated polyvinyl alcohol (PVF) sponges were performed [65]. A PVF-HA complex as a scaffold was implanted subcutaneously. PVF with rBMCs was removed from the complex and only the HA was implanted into the subcutis. Porous cylindrical HA were used as a control. After the experimental period, the amount of OC in the HA was subtracted from the total amount of OC detected in the PVF-HA complex scaffold to calculate the OC amount in the PVF sponge. The result represents the correct amount of OC in the PVF sponge.

In the porous HA used as a protector for the AL sponges, rBMCs were seeded on all inserted sponges. The cells may have penetrated into the pores of the HA. Following subcutaneous implantation of the AL-HA complex, bone formation occurred within the pores of both materials. As a result, the amount of $\mathrm{OC}$ in the HA was considered to be included in the OC amount measured in the AL gel. Thus, the amount of OC measured in the AL-HA complex should be subtracted from the total. The amount of OC in the HA was of course subtracted from the total amount in the AL-HA complex to obtain the OC amount originating from the bone formed in the AL sponge in this study.

\section{CONCLUSIONS}

The purpose of this study was to create AL sponges as scaffolds from AL gel with and without Chs to estimate osteogenesis in vitro and in vivo.

Several AL scaffolds made from AL-only gel or Chs-containing AL gel were seeded with rBMCs obtained from the rat femur. On in vitro estimation, ALP activity in the AL sponges was highly dependent on the concentrations of $\mathrm{AL}$ and $\mathrm{Chs}$ in the gel. OC was significant in scaffolds made from $10 \% \mathrm{AL}$ gel but was low in scaffolds made from the $4 \%$ gel. In vivo, scaffolds made from $10 \%$ AL gel containing $10 \%$ Chs were seeded with rBMCs and implanted subcutaneously. After removal of the scaffolds from the subcutis, the amount of OC in that scaffold was markedly high.

It was concluded that the porosity of the sponge made from the low concentration AL gel was small; however, gel concentration affect the shape of the pores. Pores in AL sponges made with higher concen- 
tration gels in a range that can be kneaded showed an appropriate size for bone formation by seeded stem cells. And, it is sure that bone formation by rBMCs is promoted in AL sponge. However, it was also concluded that it is difficult to induce bone formation in all the pores in the AL sponge.

\section{ACKNOWLEDGEMENTS}

This study was performed at the Morphological Research Facilities, Biomaterials Research Facilities, Low-Temperature Facilities, Tissue Culture Facilities, Laboratory Animal Facilities and Photograph-Processing Facilities, Institute of Dental Research, Osaka Dental University. This study was supported in part by 2015-2017 (C: 15K11140) and 2016-2018 (C: 16K11574) Grants-in-Aid for Scientific Research (C) from the Japan Society for the Promotion of Science.

The authors express their thanks to Mr. Hideaki Hori for his great support for operation and observation of SEM.

\section{CONFLICTS OF INTEREST}

The authors declare no conflicts of interest regarding the publication of this paper.

\section{REFERENCES}

1. Neel, E.A.A., Chrzanowski, W., Salih, V.M., Kim, H.W. and Knowles, J.C. (2014) Tissue Engineering in Dentistry. Journal of Dentistry, 42, 915-928. https://doi.org/10.1016/j.jdent.2014.05.008

2. Honda, J.M., Tsuchiya, S., Shinohara, Y., Shinmura, Y. and Sumita, Y. (2010) Recent Advances in Engineering of Tooth and Tooth Structures Using Postnatal Dental Cells. Japanese Dental Science Review, 46, 54-66. https://doi.org/10.1016/j.jdsr.2009.10.006

3. Chanchareonsook, N., Junker, R., Jongpaiboonkit, L. and Jansen, J.A. (2014) Tissue-Engineered Mandibular Bone Reconstruction for Continuity Defects: A Systematic Approach to the Literature. Tissue Engineering Part B, 20, 147-162. https://doi.org/10.1089/ten.teb.2013.0131

4. Taraballi, F., Bauza, G., McCulloch, P., Harris, J. and Tasciotti, E. (2017) Concise Review: Biomimetic Functionalization of Biomaterials to Stimulate the Endogenous Healing Process of Cartilage and Bone Tissue. Stem Cells Translational Medicine, 6, 2186-2196. https://doi.org/10.1002/sctm.17-0181

5. Oshima M. and Tsuji T. (2015) Whole Tooth Regeneration as a Future Dental Treatment, Advances in Experimental Medicine and Biology, 881, 255-269. https://doi.org/10.1007/978-3-319-22345-2_14

6. Kallu, R., Vinckier, F., Politis, C., Mwalili, S. and Willems, G. (2015) Tooth Transplantations: A Descriptive Retrospective Study. International Journal of Oral and Maxillofacial Surgery, 34, 745-755. https://doi.org/10.1016/j.ijom.2005.03.009

7. Na, S., Zhang, H., Huang, F., Wang, W., Ding, Y., Li, D. and Jin, Y. (2016) Regeneration of Dental Pulp/Dentine Complex with a Three-Dimensional and Scaffold-Free Stem-Cell Sheet-Derived Pellet. Journal of Tissue Engineering and Regenerative Medicine, 10, 261-270. https://doi.org/10.1002/term.1686

8. Farea, M., Husein, A., Halim, A.S., Abdullah, N.A., Mokhtar, K.I., Lim, C.K., Berahim, Z. and Mokhtar, K. (2014) Synergistic Effects of Chitosan Scaffold and TGF $\beta_{1}$ on the Proliferation and Osteogenic Differentiation of Dental Pulp Stem Cells Derived from Human Exfoliated Deciduous Teeth. Archives of Oral Biology, 59, 1400-1411. https://doi.org/10.1016/j.archoralbio.2014.08.015

9. Stoppato, M., Stevens, H.Y., Carletti, E., Migliaresi, C., Motta, A. and Guldberg, R.E. (2013) Effects of Silk Fibroin Fiber Incorporation on Mechanical Properties, Endothelial Cell Colonization and Vascularization of PDLLA Scaffolds. Biomaterials, 34, 4573-4581. https://doi.org/10.1016/j.biomaterials.2013.02.009

10. Ng, K.W., Torzilli, P.A., Warren, R.F. and Maher, S.A. (2014) Characterization of a Macroporous Polyvinyl Al- 
cohol Scaffold for the Repair of Focal Articular Cartilage Defects. Journal of Tissue Engineering and Regenerative Medicine, 8, 164-168. https://doi.org/10.1002/term.1510

11. Suárez-González, D., Barnhart, K., Saito, E., Vanderby Jr., R., Hollister, S.J. and Murphy, W.L. (2010) Controlled Nucleation of Hydroxyapatite on Alginate Scaffolds for Stem Cell-Based Bone Tissue Engineering. Journal of Biomedical Materials Research Part A, 95, 222-234. https://doi.org/10.1002/jbm.a.32833

12. Moshaverinia, A., Chen, C., Xu, X., Akiyama, K., Ansari, S., Zadeh, H.H. and Shi, S. (2014) Bone Regeneration Potential of Stem Cells Derived from Periodontal Ligament or Gingival Tissue Sources Encapsulated in RGD-Modified Alginate Scaffold. Tissue Engineering Part A, 20, 611-621.

13. Saha, D. and Bhattacharya, S. (2010) Hydrocolloids as Thickening and Gelling Agents in Food: A Critical Review. Journal of Food Science and Technology, 47, 587-597. https://doi.org/10.1007/s13197-010-0162-6

14. Déat-Lainé, E., Hoffart, V., Cardot, J.M., Subirade, M. and Beyssac, E. (2012) Development and in Vitro Characterization of Insulin Loaded Whey Protein and Alginate Microparticles. International Journal of Pharmaceutics, 439, 136-144. https://doi.org/10.1016/j.ijpharm.2012.10.003

15. Hajiali, H., Heredia-Guerrero, J.A., Liakos, I., Athanassiou, A. and Mele, E. (2015) Alginate Nanofibrous Mats with Adjustable Degradation Rate for Regenerative Medicine. Biomacromolecules, 16, 936-943. https://doi.org/10.1021/bm501834m

16. Stoppel, W.L., White, J.C., Horava, S.D., Henry, A.C., Roberts, S.C. and Bhatia, S.R. (2014) Terminal Sterilization of Alginate Hydrogels: Efficacy and Impact on Mechanical Properties. Journal of Biomedical Materials Research Part B: Applied Biomaterials, 102, 877-884. https://doi.org/10.1002/jbm.b.33070

17. Lopes, M.S., Jardini, A.L. and Filho, R.M. (2012) Poly (Lactic Acid) Production for Tissue Engineering Applications. Procedia Engineering, 42, 1402-1413. https://doi.org/10.1016/j.proeng.2012.07.534

18. Rottensteiner, U., Sarker, B., Heusinger, D., Dafinova, D., Rath, S.N., Beier, J.P., Kneser, U., Horch, R.E., Detsch, R., Boccaccini, A.R. and Arkudas, A. (2014) In Vitro and in Vivo Biocompatibility of Alginate Dialdehyde/Gelatin Hydrogels with and without Nanoscaled Bioactive Glass for Bone Tissue Engineering Applications, Materials, 7, 1957-1974. https://doi.org/10.3390/ma7031957

19. Kakigi, H., Yoshikawa, M. and Hayashi, H. (2012) Osteogenesis by Bone Marrow Cells in a Novel Hybrid Alginate/Calcium Phosphate Sponge Scaffold. Journal of Oral Tissue Engineering, 9, 113-125.

20. Dittrich, R., Despang, F., Tomandl, G., Gelinsky, M. and Pompe, W. (2006) Mineralized Scaffolds for Hard Tissue Engineering by Ionotropic Gelation of Alginate. Advances in Science and Technology, 49, 159-164. https://doi.org/10.4028/www.scientific.net/AST.49.159

21. Zimmermann, H., Hillgärtner, M., Manz, B., Feilen, P., Brunnenmeier, F., Leinfelder, U., Weber, M., Cramer, H., Schneider, S., Hendrich, C., Volke, F. and Zimmermann, U. (2003) Fabrication of Homogeneously Cross-Linked, Functional Alginate Microcapsules Validated by NMR-, CLSM- and AFM-Imaging. Biomaterials, 24, 2083-2096. https://doi.org/10.1016/S0142-9612(02)00639-7

22. Al-Otoum, R., Abulateefeh, S.R. and Taha, M.O. (2014) Preparation of Novel Ionotropically Crosslinked Beads Based on Alginate-Terephthalic Acid Composites as Potential Controlled Release Matrices. Die Pharmazie, 69, $10-18$

23. Rasool, B.K. and Fahmy, S.A. (2013) Development of Coated Beads for Oral Controlled Delivery of Cefaclor: In Vitro Evaluation. Acta Pharmaceutica, 63, 31-44. https://doi.org/10.2478/acph-2013-0003

24. Cuadros, T.R., Erices, A.A. and Aguilera, J.M. (2015) Porous Matrix of Calcium Alginate/Gelatin with Enhanced Properties as Scaffold for Cell Culture. Journal of the Mechanical Behavior of Biomedical Materials, 46, 331-342. https://doi.org/10.1016/j.jmbbm.2014.08.026

25. Yoshikawa, M., Hayami, S., Tsuji, I. and Toda, T. (1997) Histopathological Study of a Newly Developed Root 
Canal Sealer Containing Tetracalcium-Dicalcium Phosphates and 1.0\% Chondroitin Sulfate. Journal of Endodontics, 23, 162-166. https://doi.org/10.1016/S0099-2399(97)80267-1

26. Sundelacruz, S. and Kaplan, D.L. (2009) Stem Cell- and Scaffold-Based Tissue Engineering Approaches to Osteochondral Regenerative Medicine. Seminars in Cell and Developmental Biology, 20, 646-655. https://doi.org/10.1016/j.semcdb.2009.03.017

27. Yoshikawa, M., Tsuji, N., Shimomura, Y., Hayashi, H. and Ohgushi, H. (2008) Osteogenesis Depending on Geometry of Porous Hydroxyapatite Scaffolds. Calcified Tissue International, 83, 139-145. https://doi.org/10.1007/s00223-008-9157-y

28. Guicheux, J., Gauthier, O., Aguado, E., Pilet, P., Couillaud, S., Jegou, D., Daculsi, G. and Heymann, D. (1998) Human Growth Hormone Locally Released in Bone Sites Calcium-Phosphate Biomaterial Stimulates Ceramic Bone Substitution without Systemic Effects: A Rabbit Study, Journal of Bone and Mineral Research, 13, 739-748. https://doi.org/10.1359/jbmr.1998.13.4.739

29. Mastrogiacomo, M., Scaglione, S., Martinetti, R., Dolcini, L., Beltrame, F., Cancedda, R. and Quarto, R. (2006) Role of Scaffold Internal Structure on in Vivo Bone Formation in Macroporous Calcium Phosphate Bioceramics. Biomaterials, 27, 3230-3237. https://doi.org/10.1016/j.biomaterials.2006.01.031

30. Sakamoto, M. (2010) Development and Evaluation of Superporous Hydroxyapatite Ceramics with Triple Pore Structure as Bone Tissue Scaffold. Journal of the Ceramic Society of Japan, 118, 753-757. https://doi.org/10.2109/jcersj2.118.753

31. Bose, S., Roy, M. and Bandyopadhyay, A. (2012) Recent Advances in Bone Tissue Engineering Scaffolds. Trends in Biotechnology, 30, 546-554. https://doi.org/10.1016/j.tibtech.2012.07.005

32. Phadke, A., Hwang, Y., Kim, S.H., Kim, S.H., Yamaguchi, T., Masuda, K. and Varghese, S. (2013) Effect of Scaffold Microarchitecture on Osteogenic Differentiation of Human Mesenchymal Stem Cells. European Cells and Materials, 25, 114-129. https://doi.org/10.22203/eCM.v025a08

33. Du, J., Zou, Q., Zuo, Y. and Li, Y. (2014) Cytocompatibility and Osteogenesis Evaluation of HA/GCPU Composite as Scaffolds for Bone Tissue Engineering. International Journal of Surgery, 12, 404-407. https://doi.org/10.1016/j.ijsu.2014.03.005

34. De Witte, T.-M., Fratila-Apachitei, L.E., Zadpoor, A.A. and Peppas, N.A. (2018) Bone Tissue Engineering via Growth Factor Delivery: From Scaffolds to Complex Matrices. Regenerative Biomaterials, 5, 197-211. https://doi.org/10.1093/rb/rby013

35. Karageorgiou, V. and Kaplan, D. (2005) Porosity of 3D Biomaterial Scaffolds and Osteogenesis. Biomaterials, 26, 5474-5491. https://doi.org/10.1016/j.biomaterials.2005.02.002

36. Mour, M., Das, D., Winkler, T., Hoenig, E., Mielke, G., Morlock, M.M. and Schilling, A.F. (2010) Advances in Porous Biomaterials for Dental and Orthopaedic Applications. Materials, 3, 2947-2974. https://doi.org/10.3390/ma3052947

37. Klenke, F.M., Liu, Y., Yuan, H., Hunziker, E.B., Siebenrock, K.A. and Hofstetter, W. (2008) Impact of Pore Size on the Vascularization and Osseointegration of Ceramic Bone Substitutes in Vivo. Journal of Biomedical Materials Research Part A, 85, 777-786. https://doi.org/10.1002/jbm.a.31559

38. Zhang, Y., Xu, H.H., Takagi, S. and Chow, L.C. (2006) In-Situ Hardening Hydroxyapatite-Based Scaffold for Bone Repair. Journal of Materials Science: Materials in Medicine, 17, 437-445. https://doi.org/10.1007/s10856-006-8471-z

39. Zdravkov, B.D., Čermák, J.J., Šefara, M. and Janků, J. (2007) Pore Classification in the Characterization of Porous Materials: A Perspective. Central European Journal of Chemistry, 5, 385-395.

40. Ghodbane, S.A. and Dunn, M.G. (2016) Physical and Mechanical Properties of Cross-Linked Type I Collagen 
Scaffolds. Journal of Biomedical Materials Research Part A, 104, 2685-2692. https://doi.org/10.1002/jbm.a.35813

41. Takahashi, Y., Yamamoto, M. and Tabata, Y. (2005) Osteogenic Differentiation of Mesenchymal Stem Cells in Biodegradable Sponges Composed of Gelatin and Beta-Tricalcium Phosphate. Biomaterials, 26, 3587-3596. https://doi.org/10.1016/j.biomaterials.2004.09.046

42. Tiğll, R.S., Karakeçili, A. and Gümüşderelioğlu, M. (2007) In Vitro Characterization of Chitosan Scaffolds: Influence of Composition and Deacetylation Degree. Journal of Materials Science: Materials in Medicine, 18, 1665-1674. https://doi.org/10.1007/s10856-007-3066-X

43. Matsiko, A., Gleeson, J.P. and O’Brien, F.J. (2015) Scaffold Mean Pore Size Influences Mesenchymal Stem Cell Chondrogenic Differentiation and Matrix Deposition. Tissue Engineering Part A, 21, 486-497. https://doi.org/10.1089/ten.tea.2013.0545

44. O’Brien, F.J., Harley, B.A., Yannas, I.V. and Gibson, L.J. (2005) The Effect of Pore Size on Cell Adhesion in Collagen-GAG Scaffolds. Biomaterials, 26, 433-441. https://doi.org/10.1016/j.biomaterials.2004.02.052

45. Engler, A.J., Sen, S., Sweeney, H.L. and Discher, D.E. (2006) Matrix Elasticity Directs Stem Cell Lineage Specification. Cell, 126, 677-689. https://doi.org/10.1016/j.cell.2006.06.044

46. Hao, J., Zhang, Y., Jing, D., Shen, Y., Tang, G., Huang, S. and Zhao, Z. (2015) Mechanobiology of Mesenchymal Stem Cells: Perspective into Mechanical Induction of MSC Fate. Acta Biomaterialia, 20, 1-9. https://doi.org/10.1016/j.actbio.2015.04.008

47. Oliveira, J.M., Rodrigues, M.T., Silva, S.S., Malafaya, P.B., Gomes, M.E., Viegas, C.A., Dias, I.R., Azevedo, J.T., Mano, J.F. and Reis, R.L. (2006) Novel Hydroxyapatite/Chitosan Bilayered Scaffold for Osteochondral Tissue-Engineering Applications: Scaffold Design and Its Performance When Seeded with Goat Bone Marrow Stromal Cells. Biomaterials, 27, 6123-6137. https://doi.org/10.1016/j.biomaterials.2006.07.034

48. Sun, M., Chi, G., Li, P., Lv, S., Xu, J., Xu, Z., Xia, Y., Tan, Y., Xu, J., Li, L. and Li, Y. (2018) Effects of Matrix Stiffness on the Morphology, Adhesion, Proliferation and Osteogenic Differentiation of Mesenchymal Stem Cells. International Journal of Medical Sciences, 15, 257-268. https://doi.org/10.7150/ijms.21620

49. Manton, K.J., Leong, D.F., Cool, S.M. and Nurcombe, V. (2007) Disruption of Heparan and Chondroitin Sulfate Signaling Enhances Mesenchymal Stem Cell-Derived Osteogenic Differentiation via Bone Morphogenetic Protein Signaling Pathways. Stem Cells, 25, 2845-2854. https://doi.org/10.1634/stemcells.2007-0065

50. Iida, J., Meijne, M.L., Oegema, T.R. Jr., Yednocki, T.A., Kovach, N.L., Furcht, L.T. and McCarthy, J.B. (1998) A Role of Chondroitin Sulfate Glycosaminoglycan Binding Site in $\alpha_{4} \beta_{1}$ Integrin-Mediated Melanoma Cell Adhesion. The Journal of Biological Chemistry, 273, 5955-5962. https://doi.org/10.1074/jbc.273.10.5955

51. Liang, W.H., Kienitz, B.L., Penick, K.J., Welter, J.F., Zawodzinski, T.A. and Baskaran, H. (2010) Concentrated Collagen-Chondroitin Sulfate Scaffolds for Tissue Engineering Applications. Journal of Biomedical Materials Research Part A, 94, 1050-1060. https://doi.org/10.1002/jbm.a.32774

52. Yoshikawa, M. and Toda, T. (2004) In Vivo Estimation of Periapical Bone Reconstruction by Chondroitin Sulfate in Calcium Phosphate Cement. Journal of the European Ceramic Society, 24, 521-531. https://doi.org/10.1016/S0955-2219(03)00196-1

53. Lim, J.J. and Temenoff, J.S. (2013) The Effect of Desulfation of Chondroitin Sulfate on Interactions with Positively Charged Growth Factors and Upregulation of Cartilaginous Markers in Encapsulated MSCs. Biomaterials, 34, 5007-5018. https://doi.org/10.1016/j.biomaterials.2013.03.037

54. Chiba, S., Anada, T., Suzuki, K., Saito, K., Shiwaku, Y., Miyatake, N., Baba, K., Imaizumi, H., Hosaka, M., Itoi, E. and Suzuki, O. (2016) Effect of Resorption Rate and Osteoconductivity of Biodegradable Calcium Phosphate Materials on the Acquisition of Natural Bone Strength in the Repaired Bone. Journal of Biomedical Materials Research Part A, 104, 2833-2842. https://doi.org/10.1002/jbm.a.35828 
55. Bhattacharya, I., Ghayor, C. and Weber, F.E. (2016) The Use of Adipose Tissue-Derived Progenitors in Bone Tissue Engineering-A Review. Transfusion Medicine and Hemotherapy, 43, 336-343. https://doi.org/10.1159/000447494

56. Lee, K.Y. and Mooney, D.J. (2012) Alginate: Properties and Biomedical Applications. Progress in Polymer Science, 37, 106-126. https://doi.org/10.1016/j.progpolymsci.2011.06.003

57. Erdogan, N. and Eken, H.A. (2017) Precipitated Calcium Carbonate Production, Synthesis and Properties. Physicochemical Problems of Mineral Processing, 53, 57-68.

58. Chen, Q.Z., Wong, C.T., Lu, W.W., Cheung, K.M., Leong, J.C. and Luk, K.D. (2004) Strengthening Mechanisms of Bone Bonding to Crystalline Hydroxyapatite in Vivo. Biomaterials, 25, 4243-4254. https://doi.org/10.1016/j.biomaterials.2003.11.017

59. Matsuura, A., Kubo, T., Doi, K., Hayashi, K., Morita, K., Yokota, R., Hayashi, H., Hirata, I., Okazaki, M. and Akagawa, Y. (2009) Bone Formation Ability of Carbonate Apatite-Collagen Scaffolds with Different Carbonate Contents. Dental Materials Journal, 28, 234-242. https://doi.org/10.4012/dmj.28.234

60. Kimura, D., Baba, S. and Ueda, M. (2011) Efficacy of Bone Regeneration with Poly(Pro-Hyp-Gly) Synthetic Polypeptide Sponge as Scaffold Using Bone Marrow Derived Mesenchymal Stem Cells. Journal of Oral Tissue Engineering, 8, 162-172.

61. Yu, Z., Zhu, T., Li, C., Shi, X., Liu, X., Yang, X. and Sun, H. (2012) Improvement of Intertrochanteric Bone Quality in Osteoporotic Female Rats after Injection of Polylactic Acid-Polyglycolic Acid Copolymer/Collagen Type I Microspheres Combined with Bone Mesenchymal Stem Cells. International Orthopaedics, 36, 2163-2171. https://doi.org/10.1007/s00264-012-1543-4

62. George, J., Onodera, J. and Miyata, T. (2008) Biodegradable Honeycomb Collagen Scaffold for Dermal Tissue Engineering. Journal of Biomedical Materials Research Part A, 87, 1103-1011. https://doi.org/10.1002/jbm.a.32277

63. Tam, S.K., Dusseault, J., Bilodeau, S., Langlois, G., Hallé, J.P. and Yahia, L. (2011) Factors Influencing Alginate Gel Biocompatibility. Journal of Biomedical Materials Research Part A, 98, 40-52. https://doi.org/10.1002/jbm.a.33047

64. Sun, J. and Tan, H. (2013) Alginate-Based Biomaterials for Regenerative Medicine Applications. Materials, 6, 1285-1309. https://doi.org/10.3390/ma6041285

65. Yoshikawa, M., Kakigi, H., Miyamoto, A., Sugimoto, S., Nakai, K., Ikenaga, H., Inamoto, T. and Maeda, H. (2016) In Vivo Estimation of Osteogenesis by Bone Marrow Cells in a Bi-Phasic Scaffold and in Each of Its Components. Journal of Biomedical Science and Engineering, 9, 501-514. https://doi.org/10.4236/jbise.2016.911045 